\title{
A Comprehensive Approach for the Management of Virtual Enterprises Including Performance Analysis, Provision of Incentives and Allocation of Income
}

\author{
Hendrik Jähn \\ Chemnitz University of Technology, Department of Economic Sciences, \\ 09107 Chemnitz, Germany \\ hendrik.jaehn@wirtschaft.tu-chemnitz.de
}

\begin{abstract}
This conceptual paper focuses a comprehensive business model for service-oriented collaborative networks and Virtual Enterprises. In that context an innovative concept for the operative controlling of enterprises operating in order-specific configured collaborative systems is introduced. This approach includes a variety of methodologies. The main part of that approach considers income allocation based on the realised performance. Therefore a concept for the order-specific performance analysis has been developed. Additionally incentive mechanisms are considered. By the help of that approach new impulses for the operative enterprise management and controlling are available.
\end{abstract}

Keywords: Production Management, Virtual Enterprise, Performance Analysis, Business Modeling.

\section{Motivation}

An increasing number of production and supply processes are completed by collaborative systems. The reasons for that development are mainly of financial nature. However, enterprise-spanning cooperations cannot always act without frictions. Thus, an effective business model for service-oriented production and network management is required for the coordination both the cooperation and the value-adding process. Methods for the order-specific partner selection and preparation of offers are already available. However the challenging task of income allocation and process-related performance analysis mostly still remain unclear. This fact constitutes a major problem to be solved. The present contribution addresses these issues and focuses appropriate solutions.

Currently applied approaches of cooperations controlling are usually the classic corporate controlling methods. For this reason, the specific requirements of cooperation management are considered unsufficiently. This often leads to unsatisfactory results. The introduced framewerk and its methods represent an extension of the current controlling instruments. The main advantage is the high degree of adaptability. This allows a flexible applicability for the user, which is not available when standard instruments are applied. That fact represents a significant value added and expands the capabilities of cooperation management significantly. 


\section{Initial Situation, Problem Formulation and Research Object}

Actors, who track an objective on their own, are by trend less successful than those, who align themselves and cooperate. On this note, cooperation forms an important precondition for evolution, as only those persons involved will survive in the long run and establish oneself in competition successfully, who adjust best to the given environmental conditions and who apply the most effective and most successful survival strategies. Cooperation is a very successful strategy in most of the cases. With regard to economy, similar conclusions can be drawn. As a general problem statement it is obvious that cooperation needs a comprehensive framework for controlling and management. That topic is focused in the next sections.

It is clear that cooperations not only bring benefits but also incur costs. However in the following it is assumed that only cooperations form when the (additional) benefit exceed the (additional) costs. In general, although independent enterprises act successful on the market, cooperation often generates additional capabilities. These allow for an even more successful market participation, provided that those advantages are not compensated by frictional or coordination losses between the cooperating partners.

From a historic point of view, many (successful) types of cooperation and teamwork can be identified within economy. Milestones are the implementation of division of labour in production processes, cp. the example for mass production of pins [1], a consistent improvement in assembly line production within an industrial environment by Ford or the formation and operation of company cooperations in terms of company networks [2] as long-term cooperations [3] or virtual enterprises [4],[5]. Especially since the middle of the 20th century, economical motivated cooperations are studied increasingly from a scientific point of view. Whereas for the time being primarily economic problems took centre stage, referred to seminal publications of Coase in 1937 where questions of in-house production depth have been debated - a topic, which also concerns the formation of cooperations [6], since 1980 also economical and information technology-related questions of cooperation have been discussed increasingly. Especially since 1990, networks, virtual enterprises and supply chains are researched intensely, which meanwhile led to a review of general and basic circumstances and the current work focuses on more specialized problems. The article on hand belongs to this category.

In the context of the given problems explained in section 1it is necessary to localise room for improvement of the given methods or to develop new instruments. Currently, there have hardly been any scientific methods available for researching the existing problems in a specific way. Particularly the tasks after completing a valueadded process remain unclear from the scientific point of view in most cases. It is necessary to research possibilities for an improvement of the functional mains operation for manufacturing small enterprises.

The economic environment of important industrial nations, which is characterised by a great dynamic, is affected by divergent interests, as on the one hand, the single enterprises compete against each other and on the other hand, however, they form enterprise networks which take part in the competition as organisational units. Here, the single enterprises as well as the network as the whole construct quest for the maximization of utility, which normally equates the quest for profit maximisation. 
Based on that fact, different interests do exist, which need to be consorted in terms of a customer orientation. In this context, customer orientation includes a competitive price as well as the compliance of several consents, e.g. product quality and date of delivery. To reach this target, a permanent monitoring of the value-added process is necessary to be finally able to collect and evaluate the performances of the single enterprises involved in the value-added process after its completion with having regard to appropriate criteria. Against the background of this process subsequently called performance analysis (PA), the problem of the value-added process-related allocation of income (= profit / loss) which is generated by the network participants is of high importance. Undoubted in this context is the relevance of this topic, especially from a practical point of view. Indeed, many enterprises demand clear and flexible standards concerning the allocation income within networks, but for a lack of alternatives, only rough-structured or simple structured and hardly any or no situational arrangements are implemented.

Another problem arises due to the inconsistent and unclear legal framework for order specific configured collaborative networks. Those heterogeneous systems in coincidence with the network managements' point of view are mainly more strategic than operational. Therefor it must be clarified how the interests of an enterprise network as well as those of a single network participants (enterprise division) can be aligned by means of appropriate methods and concepts to ensure their long-term survival and sustainable success. Particularly, possibilities to split up profit / loss on the participating enterprises out of the networked value-added processes in a transparent, righteous and performance-related way need to be developed. In this context, possibilities for an incentive configuration and sanction mechanism for the coordination of interests of groups of actors are considered in detail.

The research project has been accomplished under consideration of a special approach for the coordination and operation of value-added networks. This concept, termed „Extended Value Chain Management” (EVCM) [7] has been developed within the research work for the Special Research Program „Non-hierarchical regional production nets" and is notably analyzing the networking of micro- and small enterprises, which are herein understood as competence cells. Those cells represent elementary organisational units of a non-hierarchical regional production network. According to the definition of the research project they are the "smallest performance unit of the value-added, which cannot be divided meaningfully anymore" [8].

The research project focuses on the organisational form of a competence cell as well as on possibilities to control order specific configured production nets by means of specific measures that a product can be manufactured, which on the one hand totally meets the customer requirements but also maximizes the utility of the enterprises cooperating. In this context approaches for an allocation of income as well as models for an evaluation of accomplished performances and possibilities of an incentive configuration are introduced. With this focussing, the object of investigation has to be ranged into the economic orientated network research with focus on production management. The central control mechanism can be pointed out as major advantage of the approach, which allows for a network management as an entity. Hence, the value-added process can be controlled and coordinated according to the customer requirements and at the same time, the different interests of the network participants can be taken into consideration. Furthermore, the EVCM is a very 
detailed and for some parts already IT-transformed operator concept, wherein the implementation of profit- and loss allocation can be integrated through an appropriate module. The mechanism of partner selection considers hard and soft-facts [9].

\section{Methodologies}

The adaptability of models and concepts can be found out on the basis of acceptance by the participating actors. A good model finds a (relatively) broad acceptance, whereas worse approaches are only hardly accepted and are therefore applied to a lesser extent. If an approach will be accepted primarily depends on the affected actors - if they perceive the approach as righteous and fair. At this point the problem arises, that justice and fairness demonstrate qualitative characteristics and are therefore hard to collect. Indeed, fairness and justice can be discussed out of a philosophical perspective, but normally the results do hardly provide any disputatious added value for economic purposes. A fair allocation of income can for example be assumed if the rules and therefore the allocation model, which quantifies the shares of the single individuals, are also considered by them as fair. A rule is then perceived as fair if decision-makers concordantly agree on the application of this standard in advance and if an equal negotiating position for all persons involved can be accepted in this situation. The theoretical foundations form the basis for the development of these models out of an economical perspective as e.g. Network Theory, Decision Theory and New Institutional Ecomonics.

The implemented research projects are based on three individual model pillars with the target to develop a comprehensive and highly adaptable model for an orderrelated allocation of profit and loss within networked production structures under special consideration of the Extended Value Chain Management-approach with integration of incentive and sanction mechanisms. In this context, the cooperation of small- and micro enterprises has been presumed and is represented through competence cells. By developing that model in form of a reference model it can be adapted to the specific needs for application within a reconfigurable production environment.

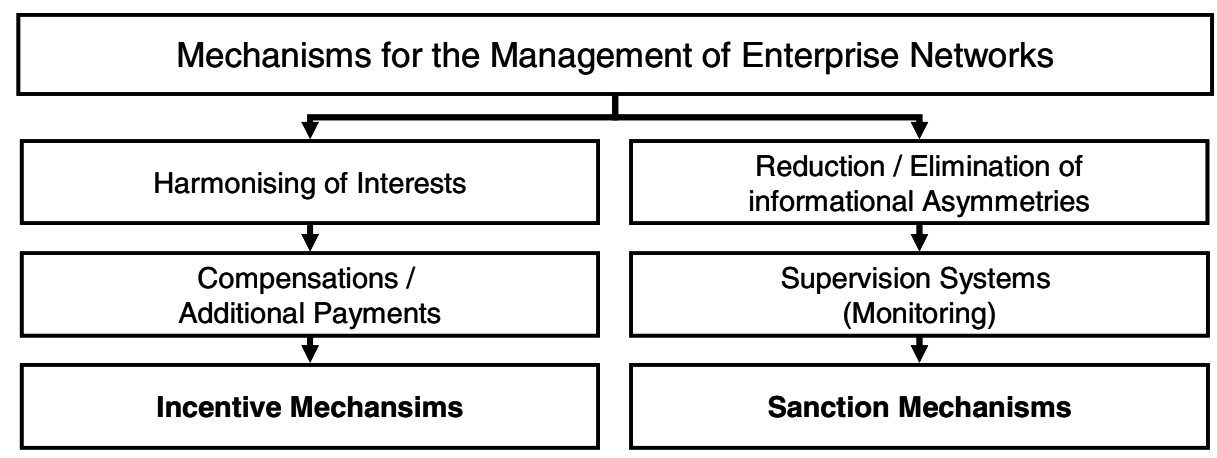

Fig. 1. Mechanisms of the operative controlling 
In figure 1 fundamentals behind incentive and sanction mechanisms are illustrated. Within the research methodology, first of relevant economic theories have been checked for its relevance. Here, the assumptions of the New Institutional Economics turned out to be an adequate cover framework [10]. Against the background of networked cooperation structures, the Principal-Agent-Theory in particular becomes very valuable [11],[12]. Within this context and under consideration of the framework of the Extended Value Chain Management-concept, possibilities of an allocation of income are focused firstly. Particularly aspects of justice with consideration of the assumption of profit maximisation of all actors play an important role. For an integration of incentive mechanisms, it has been reverted to the assumptions of the incentive theory, whereas context-specific modellings could be deviated.

Sanction mechanisms on the other hand are primarily derivable from control mechanisms, whereas the control is understood for the purpose of a performance analysis, for which extensive scopes for design are presented. Within the mathematic modelling, concrete suggestions have been made for the implementation of the developed approaches, first of all out of a theoretical perspective. The modelling of the approach of performance analysis can occur on different levels of abstraction. So there is a kind of meta-model or reference model supposable on the one hand, from which a useful approach of performance analysis can be deviated contextually and on the other hand, the deviated approaches have to be enhanced with methods, which allow a use in practice. Within the framework of the research projects, different phases of the phase model have been provided with comparatively detailed methods, so that a useable approach has been developed and simultaneously the demonstration of different approaches occurs, which allow an assimilation of the approach to changing basic conditions. In general, the performance analysis is contained here to a perspective related to the value-added process, whereby a perspective is adopted comparable to the allocation of income and incentive mechanisms, which allow for an aggregation of results of all three model pillars. Here, the focus has always been on the enterprises itself which are a part of a value-added process in form of competence cells as statutory- and economical independently acting organisations.

\section{Results of the Research Project}

The results of the research work are based on three independent model pillars with interfaces on a quantitative basis. The basic structure is illustrated in figure 2 .

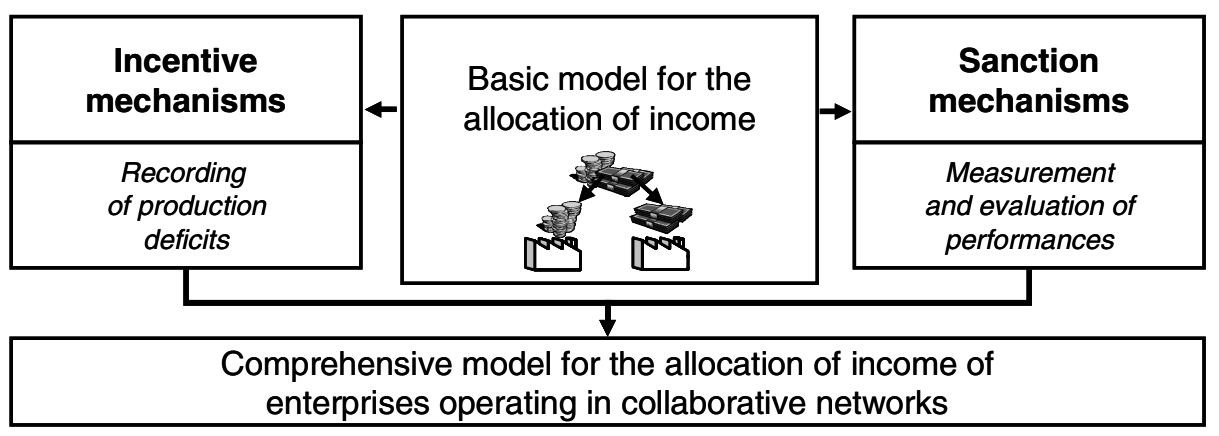

Fig. 2. Interaction of the model pillars 
First of all, the issue of methods for the allocation of income has been discussed [13]. In that context a rule-based negotiation model between customer and network representant for pricing has been developed. Consecutively different methods of resolution are deviated and demonstrated. Therefor it had to be determined, in which time frame the allocation of profit or loss is strived among the network participants. As enterprise co-operations within the EVCM-approach primarily operate order specific (for the purpose of a virtual enterprise), an allocation of income among the participating enterprises after the completion of each order was found to be the most reasonable solution. In consideration of those specific requirements, a consistent framework for the allocation of income based on partial models has been intended and completed. Those models are based primarily on fixed calculation rules and are therefore available in a quantified form. In detail, one can distinguish two-component approaches with allocation parameters, approaches with consideration of expectation of profits of the competence cells and three-component approaches with weightings. Here, different sub-models have been developed in turn. One of the components is the allocation of income according to the number of participants, to determine a constant share of income. The share of profit or loss also conforms to the portion of costs of one competence cell as a variable component and finally also according to the income conception for the purpose of an expected minimum-profit to integrate the expectations of the competence cell, as the case may be. The shares of income of the components, which need to be allocated, are either determined by use of an allocation parameter (in case of two components) or through weightings (for three components).

A further differentiation is possible regarding the conversion of allocation mechanisms. A pivotal-/ peripheral approach or a hybrid form is supposable. A peripheral approach signifies that the participating enterprises include the profits out of a value-added process into their quoted price, which means that an allocation of profits will not be necessary. Although this approach is very popular in practice, as this procedure sooner complies with the procedure of a manufacturing process which was not implemented, also severe disadvantages do exist, e.g. the inclusion of hidden earnings which can lead to exorbitant prices. The pivotal approach however allows for an instance, which coordinates the mechanisms of the allocation of profits and losses. This concept comes very near to the philosophy of the EVCM-approach.

For the configuration of incentive mechanisms in collaborative systems, the target for the permission of incentives exists in motivating the receiver of incentives to a specific action desired by the actor who provides the incentive [14]. Here, different incentive mechanisms are supposable, whereas financial incentives dominate within economy. For the accomplished research project, incentives are first of all understood as configured mechanisms originated by the network management, whereby the focus is not on a complete or extensive consideration, but selective problem areas of the (industrial) production are singled out for which possibilities for implementing financial orientated approaches will be demonstrated subsequently. Algorithmic procedures which can be applied for several network configurations stand here in the foreground. In this context, incentive mechanisms have found consideration as a designing or influencing measure. In the case of permission for incentive for competence cells, there is a direct connection to the cash flows between the network participants. So far only selected applications have been discussed and modelled. Hereto belongs for example the permission for application in case of a missing 
production capacity within the network and the configuration of incentives in case of a lacking financial attractiveness of an order.

Another important part of the whole concept are sanction mechanisms. Sanction mechanisms as an instrument for a coordination of interests of persons involved EVCM (Principal) and competence cells (Agents) - also cause cash flows between the network participants and are realized in form of control mechanisms through an approach for an order-related performance analysis of competence cells.

For the quantification of sanctions in form of a monetary amount, a comprehensive approach for the order-related measurement, evaluation and analysis of the performances accomplished by the participants of the collaborative system has been developed [15]. The claim of that approach is that in comparison to established concepts of performance evaluation not only measuring and evaluation of performances is included, but also possibilities for their analysis are considered.

The concept includes the procedure in principal based on different phases which either are value-added process-neutral or value-added process-specific. Within the value-added process-neutral phases the performance analysis is arranged and prepared through a determination of relevant performance parameters. In practice numerous parameters can potential be integrated [16]. Here, next to the performance parameters based on numbers, e.g. price, date of delivery, response time and product quality soft factors, like the cooperation performance (quality of teamwork) and confidence climate are part of the analysis as well [17]. The identification of relevant performance parameters as well as significant key figures is realized by a netbalanced scorecard. In order to represent different stages of importance the performance parameters and its evaluations are weighted repsectively. Details for the determinations of the weightings and the aspired target level of proficiency fot the performance parameters are determined as well. As a result, a key figure is calculated by means of an adapted benefit analysis, which gives information about the degree of performance of an enterprise. Based on this key figure, sanctions can be calculated in terms of a decrease of profit, if required and applicable.

Under these circumstances, accomplished performances of the competence cell are determined and evaluated by accompanying the value-added process and finally analysed in form of an aggregated key figure (actual output). In case of an inadequate value performance, which can be identified easily through a comparison of target- and actual performance, the share of profit of the affected competence cell will be reduced, which is on par with a sanction. In case of a loss there will be an additional payment. For demonstrating the connection between the degree of performance and the area of sanction, mathematic functions are applied. Furthermore, this approach has been specified further through the introduction of general applicable weighting functions for the single performance parameters, whereby a universal model framework has been created.

\section{$5 \quad$ Conclusions and Further Research}

This contribution introduced an innovative framework for the operative controlling of collaborative systems. That approch is already available in a more detailed manner including clear results and detailed approaches. However the presentation of these 
concrete mechanisms was not part because of the character of a conceptual papaer. By applying the methods included in the concept introduced, a variety of tools for the allocation of income in combination with incentive and sanction mechanisms are available. The selection of the suitable models has to be made by the particular decision makers themselves depending on the situation occurring. To allow a universal applicability of the models it has been paid attention thereon that a custom made assimilation is normally possible without any further model modification. This especially will be realized thereby that the models could be implemented on a quantitative stage and are therefore easily controllable through selected parameters. It hereby succeeded to expand the operative network controlling with new innovative models and methods of management.

Further research work includes a verification of the assumptions based on empirical data. Furthermore, the existent impairments and limits of modelling are to eliminate. That includes limited number of performance parameters as well as questions of a determination of allocation parameters. For example it is planned to include an ecological performance parameter. Finally after completing the modelling the information-technical implementation and its practical application is planned.

\section{References}

1. Smith, A.: An Inquiry into the Nature and Causes of the Wealth of Nations, 5th edn. Methuen \& Co. Ltd., London (1904)

2. Miles, R.E., Snow, C.C.: Organizations: New concepts for new forms. California Management Review 28, 62-73 (1986) (Spring Edition)

3. Zheng, L., Possel-Dölken, F.: Strategic Production Networks. Springer, Heidelberg (2002)

4. Davidow, W.H., Malone, M.S.: The Virtual Corporation, Structuring and Revitalizing the Corporation for the 21st Century. HarperCollinsPublishers, New York (1992)

5. Byrne, J.A.: The virtual corporation. International Business Week, 36-40 (February 8,1993)

6. Coase, R.H.: The Nature of the Firm. Economica 4, 386-405 (1937)

7. Teich, T.: Extended Value Chain Management - Ein Konzept zur Koordination von Wertschöpfungsnetzen. Verlag der GUC, Chemnitz (2003)

8. Müller, E.: Production planning and operation in competence-cell-based networks. Production Planning \& Control 17, 99-112 (2006)

9. Fischer, M., Jähn, H., Teich, T.: Optimizing the selection of partners in production networks. Int. J. Robotics and Computer-Integrated Manufacturing 20(6), 593-601 (2004)

10. Furubotn, E.G., Richter, R.: Institutions and Economic Theory: The Contribution of the New Institutional Economics, 2nd edn. University of Michigan Press, Ann Arbor (2005)

11. Ross, S.A.: The Economic Theory of Agency: The Principal's Problem. American Economic Review 63, 134-139 (1973)

12. Jensen, M.C., Meckling, W.H.: Theory of the Firm: Managerial Behaviour, Agency Costs and Ownership Structure. Journal of Financial Economics 3, 305-360 (1976)

13. Jähn, H., Burghardt, T.: Fundamentals for the Allocation of Financial Benefits in Virtual Enterprises. In: Camarinha-Matos, L.M., Xu, L., Afsarmanesh, H. (eds.) PRO-VE 2012. IFIP AICT, vol. 380, pp. 539-547. Springer, Heidelberg (2012) 
14. Jähn, H.: The Application of Incentive Mechanisms for the Participation of Enterprises in Collaborative Networks from an Economic Perspective. In: Camarinha-Matos, L.M., Boucher, X., Afsarmanesh, H. (eds.) PRO-VE 2010. IFIP AICT, vol. 336, pp. 773-780. Springer, Heidelberg (2010)

15. Jähn, H.: Value-added process-related performance analysis of enterprises acting in cooperative production structures. Production Planning \& Control 20, 178-190 (2009)

16. Feldmann, A., Olhager, J., Persson, F.: Designing Manufacturing Networks - An Empirical Study. In: Olhager, J., Persson, F. (eds.) Advances in Production Management Systems. IFIP, vol. 246, pp. 95-102. Springer, Boston (2007)

17. Jähn, H.: Quantitative Analysis of the Soft Factor Cooperation Climate in Collaborative Networks. In: Camarinha-Matos, L.M., Picard, W. (eds.) Pervasive Collaborative Networks. IFIP, vol. 283, pp. 65-72. Springer, Boston (2008) 